\title{
Foreword to the special issue of the Journal of Solid State Electrochemistry
}

\author{
Diana Golodnitsky ${ }^{1}$
}

Published online: 10 October 2017

(C) Springer-Verlag GmbH Germany 2017

The symposium, focused on advanced and novel battery technologies for hybrid and wholly electric vehicles is the first one on such a subject organised in the framework of the meetings of the European Materials Research Society. The symposium brought together the research community, which deals with the ways to overcome the current limitations related to the challenges concerning battery materials, their performance and ageing phenomena connected to EV application.

This special issue of the Journal of Solid State Electrochemistry contains a selection of the papers presented at Symposium N of the EMRS Fall 2016 meeting. The selected articles fairly represent the main electrochemistry sections covered during the meeting: nanostructured electrode materials for Li-ion batteries, development of "green" and safe electrolyte chemistries for Li-ion batteries, post-lithium-ion batteries, understanding the ageing and degradation processes with the help of modelling.

We sincerely thank all participants for their excellent scientific contributions and for making Symposium $\mathrm{N}$ of the EMRS Fall 2016 meeting a memorable one!
Diana Golodnitsky

golod@post.tau.ac.il

1 School of Chemistry, Raymond and Beverly Sackler Faculty of Exact Sciences, Tel Aviv University, Ramat Aviv, 6997801 Tel Aviv, Israel 